\title{
$\beta$-Endorphin/ACTH Immunocytochemistry in the CNS of the Lizard Anolis carolinensis: Evidence for a Major Mesencephalic Cell Group
}

\author{
HENRY KHACHATURIAN, ROBERT M. DORES, STANLEY J. WATSON, \\ AND HUDA AKIL \\ Mental Health Research Institute, University of Michigan, Ann Arbor, Michigan 48109
}

\begin{abstract}
The immunocytochemical distribution of $\beta$-endorphin and other proopiomelanocortin (POMC) peptides in the central nervous system of the lizard Anolis carolinensis was determined. Colchicine pretreatment was used to enhance perikaryal immunoreactivity. A major finding of this study is the localization of a previously undetected mesencephalic cell group which exhibits immunoreactivity to $\beta$-endorphin, $\mathrm{ACTH}$, and $\alpha$-MSH. The perikarya of these neurons are large, bipolar, and situated in the mesencephalic tegmental area. They appear to project to the mesencephalic central gray and other brainstem structures. In contrast, the immunoreactive parvicellular perikarya of the medial-basal hypothalamus, corresponding to the POMC perikarya of the rodent arcuate nucleus, exhibit major rostral projections to various telencephalic and diencephalic structures. The exact extent of fiber projections and innervation patterns arising from either of these two groups is not clear at this time and will require further analyses. Scattered fiber immunoreactivity was also seen in the medial cerebral cortex and the striatal complex, regions which apparently are not innervated by $\beta$-endorphin fibers in the rodent brain. Also, no immunoreactivity was seen to an antiserum to the $16 \mathrm{~K}$ peptide of POMC. Other similarities and differences in the brain distribution of POMC in reptiles and mammals are discussed.
\end{abstract}

Key words: $\beta$-endorphin, ACTH, lizard brain, immunocytochemical

Studies on the anatomical distribution of the opioid $\beta$ endorphin and related peptides in the central nervous system have primarily focused on the mammalian brain, especially the rodent (Watson et al., '78; Bloom et al., '78; Jacobowitz and O'Donohue, '78; Nilaver et al., '79; Sofroniew, '79; Finley et al., '81; Khachaturian et al., '84). $\beta$ endorphin, a potent opioid ( $\mathrm{Li}$, '81) synthesized in both endocrine and neural tissue (Eipper and Mains, ' 80 ; Kreiger et al., ' 80 ), is derived from the poly protein proopiomelanocortin (POMC), the common precursor for ACTH-, $\alpha$-MSH-, and $\beta$-lipotropin-related end products, as well as $\beta$-endorphin (Mains et al., '77; Roberts and Herbert, '77; Nakanishi et al., '79). There is convergent pharmacological and physiological evidence that $\beta$-endorphin and some of the other end products of POMC may be involved in the regulation of pain and stress, endocrine and cardiovascular control, respiration, and thermoregulation (O'Donohue and Dorsa, ' 82 ). These functions, which have been ascribed to the limbic system and brainstem, are consistent with the anatomical distribution of $\beta$-endorphin in the brain of mammals (see Khachaturian et al., '84).

The majority of studies on the distribution of $\beta$-endorphin in the brain have focused on mammals; relatively few studies have focused on the representatives of other classes of vertebrates. Studies on the comparative anatomy of $\beta$-endorphin in the brain of nonmammalian vertebrates may not only provide information on the phylogeny of this system but may also provide insights into the physiological functions of $\beta$-endorphin in the brain. Currently, the comparative approaches have been limited to studies on the hypothalamus of two fish species (Dubois et al., '79; Follenius and Dubois, '79) and one amphibian species (DoerrSchott et al., '81). However, relatively little is known about the distribution of POMC-related peptides in the brains of reptiles. The present study will consider the anatomical

Accepted July 18, 1984. 
distibution of these substances in the brain of the lizard Anolis carolinensis. Previous studies have focused on the localization and partial characterization of $\beta$-endorphin and several ACTH-related end products in the anterior and intermediate pituitary of this species (Dores, '82a,b, '83; Dores and Suprenant, ' 83 , ' 84 ). The present study considers the anatomical distribution of these peptides in the reptile brain.

\section{MATERIALS AND METHODS}

Adult male Anolis carolinensis (3-5 gm wet weight) specimens were purchased from the Carolina Biological Supply Co. The animals were held on a dark background at $30^{\circ} \mathrm{C}$. under constant illumination for 7 days prior to experimentation.

Some animals were pretreated with colchicine prior to death to enhance the visualization of neuronal perikarya (Fink et al., '73; Kreutzberg, '69). For this purpose, each animal was anesthetized with ether before the injection. The colchicine injection apparatus consisted of a plastic tube attached at one end to a 30-gauge needle and a Hamilton microsyringe at the other end. Colchicine solutions of varying concentrations (5-25 $\mu \mathrm{g}$ per $5 \mu \mathrm{l}$ normal saline) were tested in individual animals. Injections were made into the right lateral cerebral ventricle of the anesthetized lizard. The animal was allowed to recover from the anesthesia and then was placed back into the colony for a period of 24-48 hours. The ventricular injection was confirmed histologically.

Both normal and colchicine-treated animals were reanesthetized prior to perfusion, and each animal was placed on a bed of crushed ice. Immediately thereafter, the chest cavity was exposed and the cardiovascular system was flushed via the cardiac ventricles with ice-cold normal saline followed by $50-100 \mathrm{ml}$ of ice-cold neutral buffered $4 \%$ paraformaldehyde delivered in a 50-ml syringe. The head was then severed from the trunk and placed in a dish under a dissecting microscope. The brain was then removed and postfixed in the same fixative for periods of up to 2 hours, transferred into a $15 \%$ sucrose solution, and stored for an additional 24 hours at $4^{\circ} \mathrm{C}$. Brains were placed in an embedding medium (O.C.T., Tissue Tek) and immersed into liquid nitrogen until frozen. Frozen brain sections of $20 \mu \mathrm{m}$ were obtained with a cryostat, and the tissue was thawmounted onto subbed glass slides and stored at $-70^{\circ} \mathrm{C}$ prior to use. Every tenth section was stained with a Nissl stain for anatomical orientation (see below).

For immunocytochemistry, the tissue sections were allowed to dry at room temperature and then were processed for PAP immunocytochemistry as described by Khachaturian et al. ('82). Briefly, the sections were incubated (at $37^{\circ} \mathrm{C}$ ) with normal goat serum (NGS, from GIBCO) for 5 10 minutes, drained, and incubated with primary rabbit antiserum raised against each POMC peptide fragment ( $\beta$ endorphin, ACTH, $\alpha-\mathrm{MSH}$, and $16 \mathrm{~K}$ ) diluted in $0.02 \mathrm{M}$ phosphate-buffered saline (PBS) and 0.3\% Triton X-100. Several sections were used as controls, which were incubated with antiserum preadsorbed with up to $50 \mu \mathrm{M}$ concentrations of either the primary peptide or other peptides with similar amino acid sequences in a cross-blocking paradigm. After a one-hour incubation, the sections were transferred onto wet foam rubber in moist-boxes and stored overnight at $4^{\circ} \mathrm{C}$. The second day of the procedure consisted of several PBS washes followed by incubation $\left(37^{\circ} \mathrm{C}\right)$ of the sections with goat antirabbit serum (Arnel) for 30 minutes. The sections were again refrigerated overnight in moist-boxes.
The following day, the sections were washed in PBS, incubated with rabbit anti-HRP (horseradish peroxidase) serum for 40 minutes, washed in PBS, and incubated with $4 \mu \mathrm{g} / \mathrm{ml}$ HRP enzyme (Sigma, type VI) for an additional 40 minutes. The sections were subsequently washed in PBS and reacted in a solution of $0.125 \mathrm{mg} / \mathrm{ml}$ diaminobenzidine tetrahydrochloride (Sigma) and $0.03 \% \mathrm{H}_{2} \mathrm{O}_{2}$ for 15 minutes. After being washed in distilled water and brief osmication $(0.01 \%$ osmium tetroxide), the sections were dehydrated through graded ethanols and xylenes, then mounted in Permount for observations with a Leitz Orthoplan microscope.

Frontal and parasagittal maps were made from the Nisslstained brain sections, upon which the observed immunoreactivity was schematically illustrated (Figs. 1-16). Several articles and atlases were consulted for neuroanatomical orientation (Butler and Northcutt, '73; Cruce,

\begin{tabular}{|c|c|}
\hline & Abbreviations \\
\hline III & Oculomotor nerve \\
\hline $\mathrm{X}$ & Dorsal motor nucleus of vagus \\
\hline A & Aqueduct \\
\hline $\mathrm{AC}$ & Anterior commissure \\
\hline $\mathrm{ACB}$ & Nucleus Accumbens \\
\hline AMG & Amygdala \\
\hline ARC & Arcuate nucleus \\
\hline BST & Bed nucleus of stria terminalis \\
\hline CBL & Cerebellum \\
\hline $\mathrm{CC}$ & Central canal \\
\hline $\mathrm{CG}$ & Central gray \\
\hline $\mathrm{DCX}$ & Dorsal cortex \\
\hline $\mathrm{DH}$ & Dorsal horn \\
\hline DM & Dorsomedial nucleus of thalamus \\
\hline DMH & Dorsomedial nucleus of hypothalamus \\
\hline DMN & Deep mesencephalic nucleus \\
\hline DVR & Dorsal ventricular ridge \\
\hline IP & Interpeduncular nucleus \\
\hline LC & Locus coeruleus \\
\hline LFB & Lateral forebrain bundle \\
\hline LGN & Lateral geniculate nucleus \\
\hline LHA & Lateral hypothalamic area \\
\hline LN & Lentiform nucleus of thalamus \\
\hline LRN & Lateral reticular nucleus \\
\hline $\bar{M}$ & Mammillary nuclei \\
\hline $\mathrm{MCX}$ & Medial cortex \\
\hline $\mathrm{MFB}$ & Medial forebrain bundle \\
\hline MLF & Medial longitudinal fasciculus \\
\hline MTA & Mesencephalic tegmental area \\
\hline NDB & Nucleus of the diagonal band \\
\hline NR & Nucleus ruber \\
\hline NTS & Nucleus tractus solitarius \\
\hline $\mathrm{OC}$ & Optic chiasm \\
\hline OLT & Olfactory tubercle \\
\hline $\mathrm{OT}$ & Optic tract \\
\hline POA & Preoptic area \\
\hline PTA & Pretectal area \\
\hline PVH & Periventricular hypothalamus \\
\hline PVN & Paraventricular nucleus \\
\hline RI & Nucleus raphe inferior \\
\hline RN & Reticular nucleus \\
\hline RO & Nucleus rotundus \\
\hline RS & Nucleus raphe superior \\
\hline $\mathrm{S}$ & Septum \\
\hline $\mathrm{SC}$ & Spinal cord \\
\hline SM & Stria medullaris \\
\hline $\mathrm{SN}$ & Substantia nigra \\
\hline SON & Supraoptic nucleus \\
\hline $\mathrm{STN}$ & Spinal trigeminal nucleus \\
\hline STR & Striatum \\
\hline $\mathrm{T}$ & Tectum \\
\hline $\mathrm{V}$ & Ventricle \\
\hline VH & Ventral horn \\
\hline VL & Ventrolateral nucleus of thalamus \\
\hline VM & Ventromedial nucleus of thalamus \\
\hline VMH & Ventromedial nucleus of hypothalamus \\
\hline VN & Vestibular nuclei \\
\hline
\end{tabular}




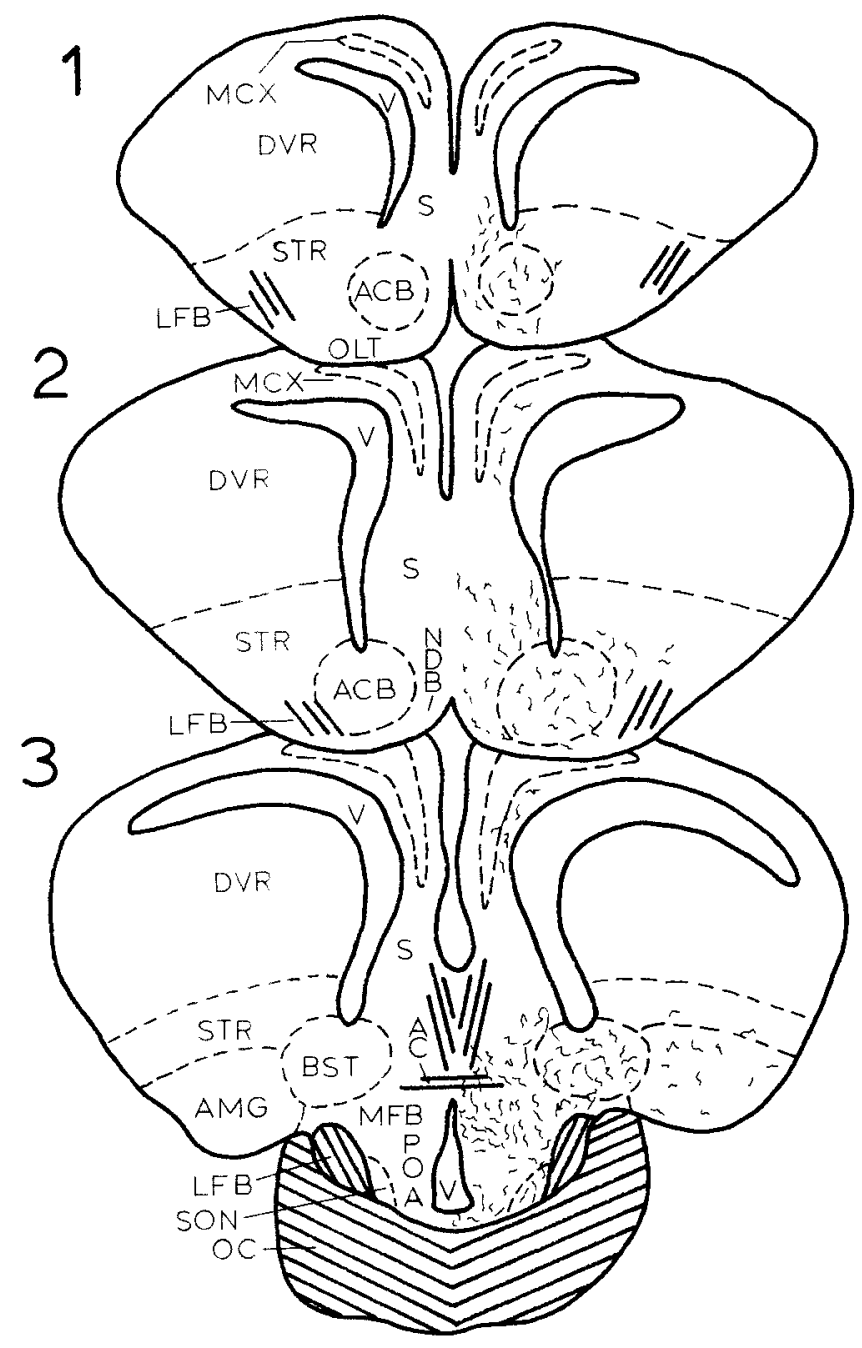

Figs. 1-12. Schematic frontal sections through the brain of A. carolinensis depicting the distribution of immunoreactive POMC-peptide-containing neuronal processes (short curved lines) and perikarya (solid rounded structures in Figures 4 and 7). The fiber densities are meant to be proportional from region to region. See list of abbreviations for details.

'74; Northcutt, '78; Naik et al., '81; Greenberg, '82). The nomenclature used was adapted from Naik et al. ('81), since the latter work provides a complete rostral-caudal atlas of brain structures.

\section{RESULTS}

The antisera used in the present study have been characterized in previous studies on rodent POMC systems (see Watson et al., '80). All immunoreactivity seen with a particular antiserum was blockable by the preadsorption of the primary antibody by $1 \mu \mathrm{M}$ concentration of the peptide against which the serum was raised (Fig. 19). Furthermore, cross-blocking studies also demonstrated the specificity of each antiserum; i.e., peptides having amino acid sequences moderately at variance with the "primary" peptide failed to block the immunostaining when added to the primary antiserum in concentrations up to $50 \mu \mathrm{M}$. For example, $\beta$ endorphin immunostaining was not blocked by met- or leu-

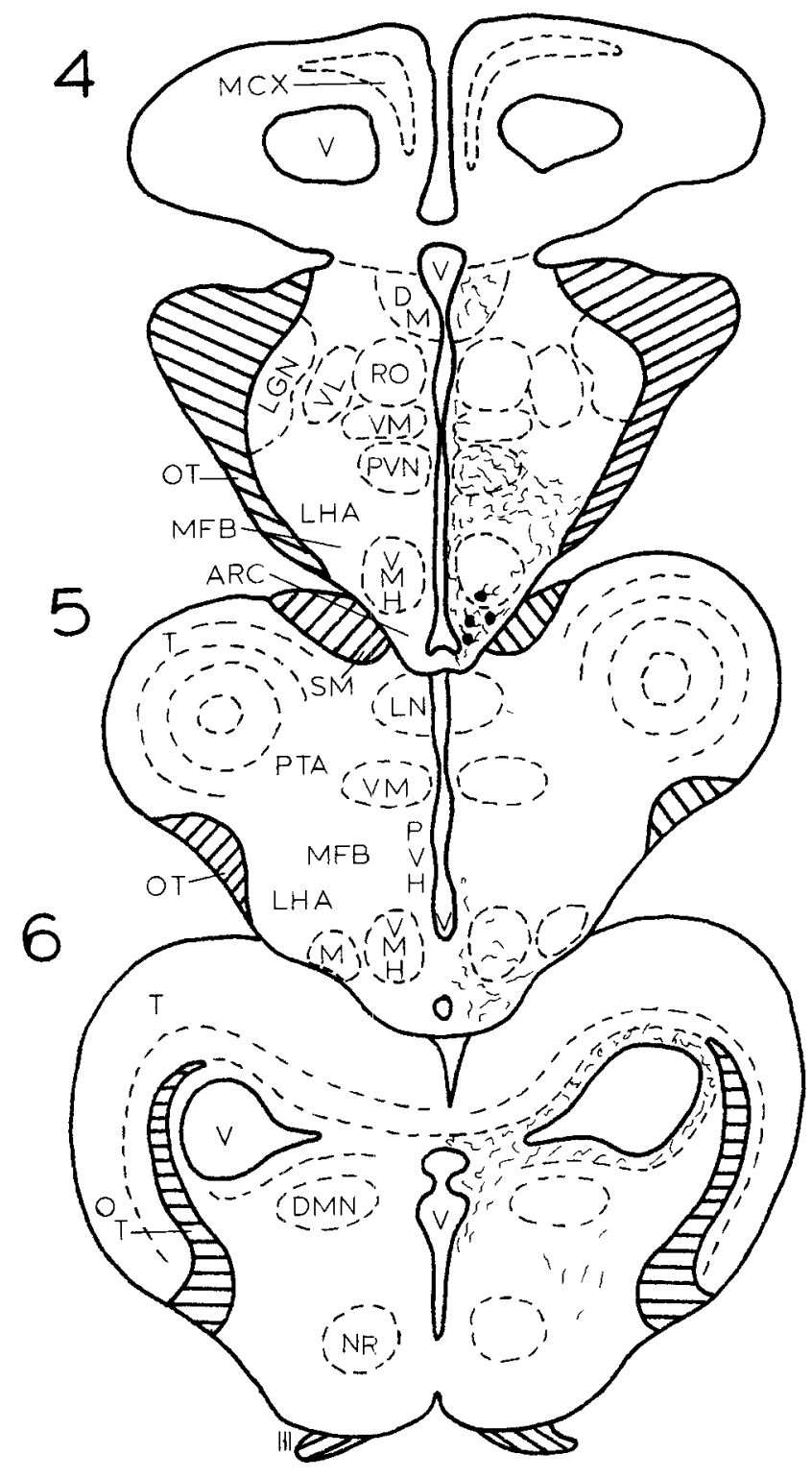

enkephalin, ACTH, or $\alpha$-MSH. The ACTH antiserum specific for ACTH(20-24) could be blocked by ACTH(1-24), -(139), -(11-24), -(11-39), but not by ACTH(11-19), $\beta$-endorphin, $\alpha$-MSH, or Met-enkephalin. Furthermore, the $\alpha$-MSH immunoreactivity was not blocked by ACTH(1-24), -(1-39), (17-39), or $\beta$-endorphin.

The immunoreactivity seen in both perikarya and fibers appeared identical for all the antisera used, with the exception of the $16 \mathrm{~K}$ antiserum, which yielded no immunostaining. The patterns of immunoreactivity were similar regardless of the antiserum used; that is, $\beta$-endorphin, ACTH, and $\alpha$-MSH immunoreactivities were localized to neuronal perikarya and projections in the same brain regions (Figs. 1-16). Interestingly, the anti-ACTH serum "stained" perikarya preferentially, while neuronal processes were better visualized with the anti- $\beta$-endorphin serum. The immunostaining obtained with the anti- $\alpha$-MSH serum was less pronounced in both perikarya and fibers. 


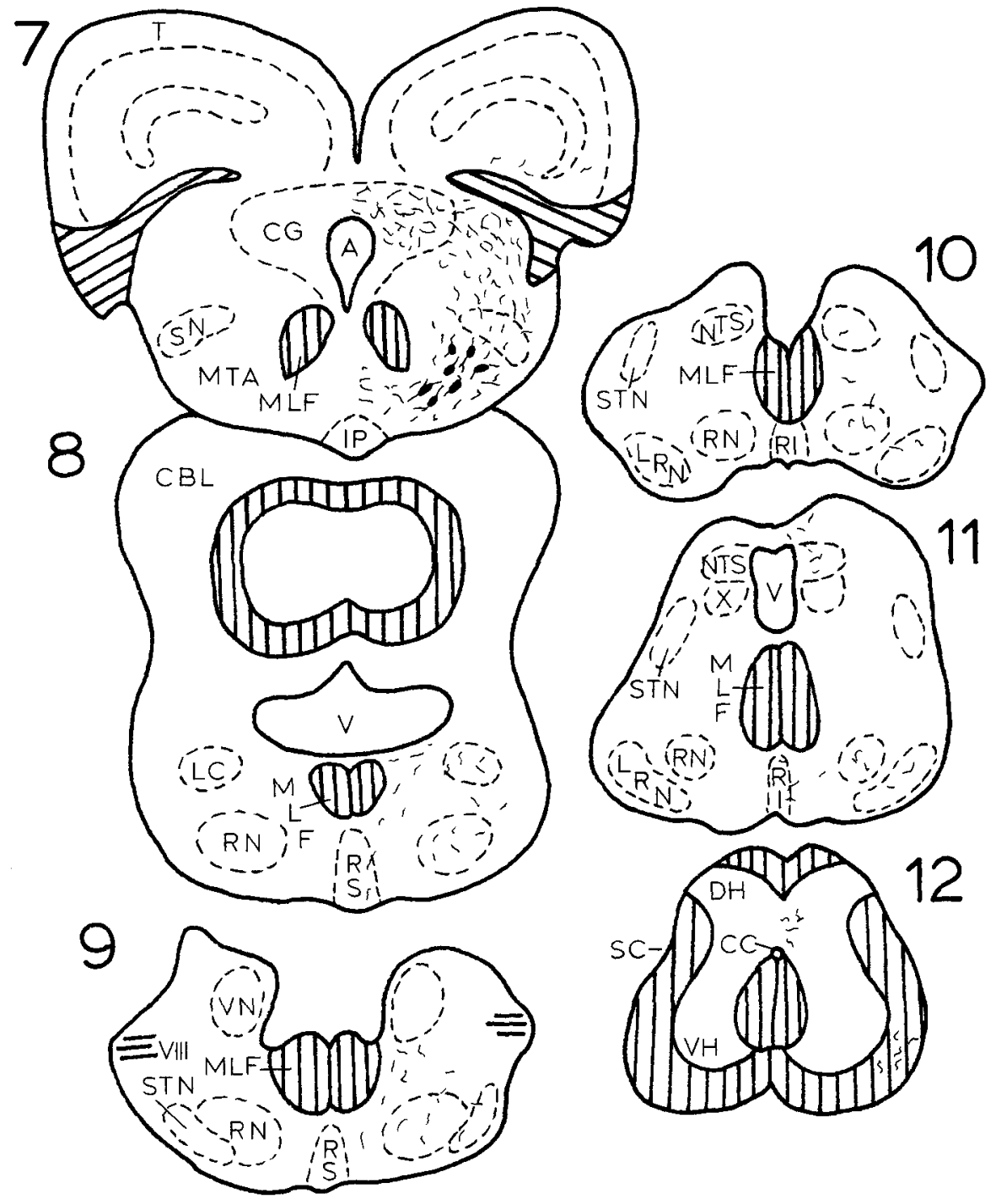

Furthermore, colchicine pretreatment appeared to enhance perikaryal immunoreactivity; the best results were seen in animals treated with $25 \mu \mathrm{g}$ colchicine for 48 hours (see Fig. 18). These results were not due to artifacts which may arise from tissue damage caused by direct intracerebral injection of colchicine (Goldschmidt and Steward, '82), since (1) colchicine was administered intracerebroventricularly and was thus distributed widely and more dilute than a local injection, and (2) identical blocking results were obtained in both normal and treated animals (see also discussion in Khachaturian et al., '82).

Perhaps the most striking observation in the present study is the localization of immunoreactive perikarya in the midbrain reticular formation. These perikarya are large (15-20 $\mu \mathrm{m}$ in length), bipolar in shape, and situated in the ventral-lateral mesencephalic tegmental area (Figs. 7, 13, $14,18,19 \mathrm{~A}, 20 \mathrm{~B})$. Furthermore, since the latter neurons are situated in the vicinity of the substantia nigra and other tegmental dopamine-containing neurons, several consecutive sections were analyzed for possible overlap of $\beta$-endorphin/ACTH perikarya and those containing tyrosine hydroxylase immunoreactivity. The preliminary results in- dicate that the two sets of neurons, i.e., $\beta$-endorphin/ACTHcontaining and catecholamine-containing, are clearly separable. Whether or not some perikarya contain both immunoreactivities must await further colocalization studies. Interestingly, this group of immunoreactive $\beta$-endorphincontaining perikarya appears to be the larger of two groups in the lizard brain, since relatively fewer perikarya were observed in the arcuate region of the hypothalamus. In the latter area, immunoreactive perikarya were seen scattered in the medial-basal hypothalamus, some even in the ventral regions of the ventromedial nucleus (Figs. 4, 15, 16, 17C). The hypothalamic perikarya are parvicellular (6-10 $\mu \mathrm{m}$ in length), often bipolar in shape, and exhibit one or two processes. Occasionally, one of the processes was seen to bifurcate a short distance away from the perikaryon. Most other processes elsewhere in the brain appeared in the form of beaded fibers running in various directions, often in groups forming projections (Figs. 17A,B, 20A, 21).

A major rostral projection can be discerned in the midline forebrain (Figs. 1-3, 17A,B). Fibers contributing to this system appear to arise from perikarya in the medial-basal hypothalamus. Immunoreactive fibers are seen to inner- 

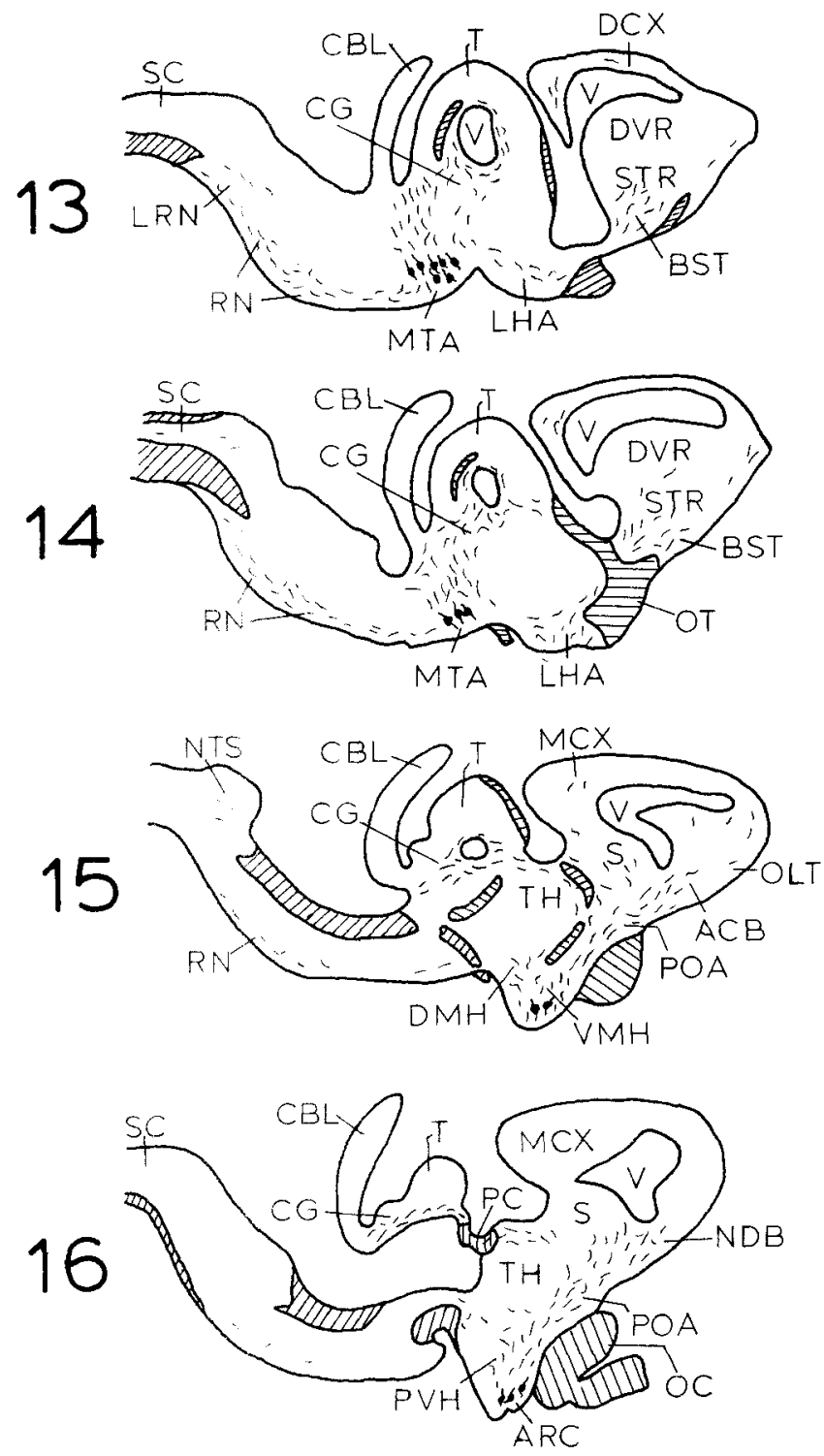

Figs. 13-16. Schematic parasagittal sections through the brain of $A$ carolinensis showing fiber and perikaryal distributions as described in Figures 1-12. See list of abbreviations for details.

vate periventricular areas of the hypothalamus (Figs. 4, 5, 16), and they extend more rostrally to innervate preoptic nuclei, both medial and lateral (Figs. 3, 15, 16, 17A). Further rostrally projecting fibers enter the telencephalon ventrally, many coursing through the medial forebrain bundle (Figs. 3, 16), while others enter the diagonal band and its associated nucleus (Figs. 2, 16). Areas innervated by these telencephalic fibers include the bed nucleus of the stria terminalis (Figs. 3, 13, 14, 17A), the septal nuclei in their ventral-lateral aspect (Figs. 1-3, 15, 16, 17A), the nucleus accumbens (Figs. 1, 2, 15), the olfactory tubercle (Figs. 1, 15), and other scattered fibers in the striatum and the medial cortex (Figs. 1-3, 13-15).

Lateral projections from the immunoreactive perikarya in the arcuate region appear to course through the lateral hypothalamic area and the supraoptic nucleus, over the optic tracts, and into the amygdala area, which exhibits scattered fiber immunoreactivity (Fig. 3).

Dorsal projections in the rostral diencephalon extend through the midline thalamus and run caudally to enter the tectum and the central gray of the mesencephalon (Figs. $6,7,13-16,21 \mathrm{~A}, \mathrm{~B})$. Other dorsally projecting fibers in the hypothalamus contribute to the innervation of the periventricular, paraventricular, dorsomedial, and posterior hypothalamic nuclei (Figs. 3-5, 15, 16, 17B).

Caudal projections from the arcuate perikarya appear to be limited in dimension and confined to the ventral diencephalon and scattered in the rostral ventral mesencephalon (Figs. 5, 6, 15, 16). In contrast, most mesencephalic and other brainstem and spinal cord regions appear to be innervated by immunoreactive fibers arising from the group of neurons in the mesencephalic tegmental area (Figs. 7-16, 20, 21C). From the mesencephalic perikarya, immunoreactive fibers form a distinct dorsal projection which courses laterally and dorsally in the ventral mesencephalon, then turns medially in the dorsal mesencephalon to innvervate the central gray (Figs. 7, 13, 14, 20A, 21A). Other fibers extend laterally and dorsally into the tectum and course in the deepest layers surrounding the ventricular extension into the tectum (Figs. 6, 13, 21B). Caudal to the central gray area, other scattered fibers are seen in the pontine and medullary reticular formation (Figs. 8-16). Another, somewhat less distinct, caudal projection from the immunoreactive mesencephalic perikarya enters the pons in its ventralmost aspect. This projection continues in the ventral medulla and then enters the spinal cord (Figs. 8-16, 21C). In the pons and medulla, this latter projection contributes to the innervation of the reticular formation, including the reticular nucleus (Figs. 8-11, 13-15, 21C), superior and inferior raphe nuclei (Figs. 8-11), as well as the lateral reticular nucleus and the nucleus tractus solitarius (Figs. $10,11,13,15)$. The nucleus tractus solitarius might also be innervated by more dorsally projecting fibers. We were unable to localize POMC-like immunoreactivity in the perikarya of the nucleus tractus solitarius as reported in the rodent (Schwartzberg and Nakane, '83; Khachaturian et al., '84). This may or may not be due to the inherent technical difficulties in demonstrating the latter cell group in the rat brain, which often requires relatively higher doses or local injections of colchicine for visualization.

In the cervical spinal cord, scattered immunoreactive fibers were also seen in the region of the central canal in the gray substance, and in the white matter, localized in the ventral lateral funiculus, adjacent to the ventral horn (Figs, $12,14)$.

\section{DISCUSSION}

The present study demonstrates the distribution of $\beta$ endorphin/ACTH immunoreactivity in the central nervous system of the lizard, Anolis carolinensis. The antisera used in this study were generated against several of the POMC peptides from mammalian sources. In general, the distribution of immunoreactivity using these antisera yielded similar results with the notable exception of the anti-16K serum, which showed no immunoreactive structures in the brain. These results are consistent with studies on the POMC system in the reptile pituitary which suggest that significant structural differences exist between the $16 \mathrm{~K}$ fragment in mammals and that found in the lizard, so as to render the latter immunologically undetectable by the antiserum used (Dores, '82a). 

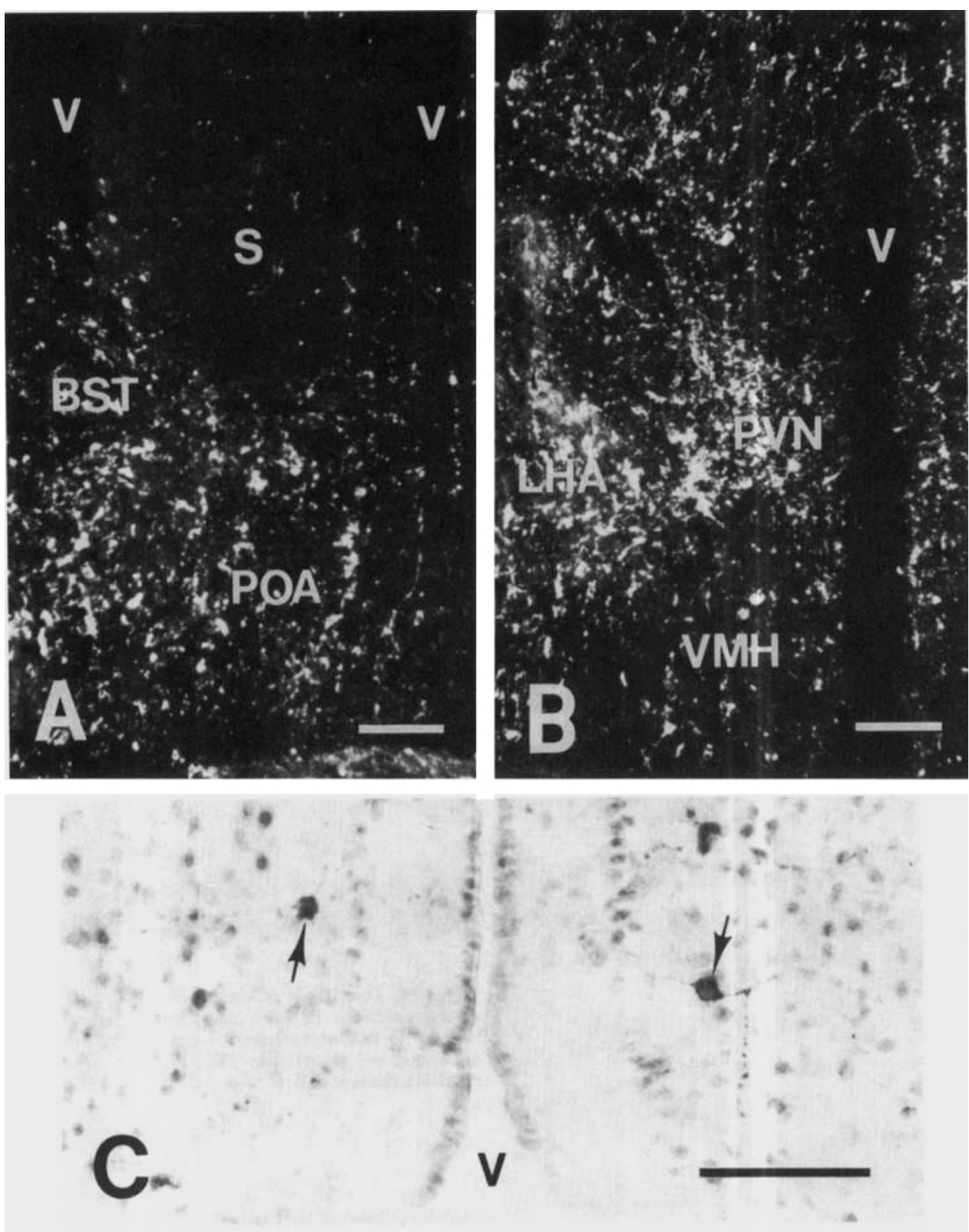

Fig. 17. In darkfield photomicrographs through the preoptic area (A) and the hypothalamus (B) $\beta$-endorphin immunoreactive fibers are shown. The third ventricle can be seen at right of each panel, $A$ and $B$; the lateral ventricle in panel $A$ is at left. In panel C, ACTH immunoreactive perikarya (arrows) exhibiting various processes can be seen in arcuate nucleus of the hypothalamus from a colchicine-pretreated animal. See list of abbreviations. Bars $(A$ and $B)=100 \mu \mathrm{m}$; bar $(C)=50 \mu \mathrm{m}$.
Perhaps the single most unusual, and therefore significant, finding in this paper is the detection of immunoreactivity within perikarya of neurons localized in the mesencephalic reticular formation. Since there are no previous reports of POMC peptide distribution in the lizard central neurons system, it seems pertinent to compare and contrast the findings of the present study with those reported for the mammalian brain, especially in the rodent.

When comparing the distribution of POMC peptide immunoreactivity within the lizard and rodent brains, striking similarities and differences can be discerned. At first glance, it appears that $\beta$-endorphin/ACTH immunoreactivity is distributed fairly similarly in both brains. In both, immunoreactive perikarya are present in the medial-basal hypothalamus. However, in the rodent, this latter cell group, situated mainly in the arcuate nucleus, is by far the largest POMC-producing neuron population in the brain. This may not be the case in the lizard, in which scattered immunoreactive perikarya are seen in the arcuate region as well as in the ventral regions of the ventromedial nucleus of the hypothalamus. A second population of POMC peptide-containing neurons was detected in the ventral 

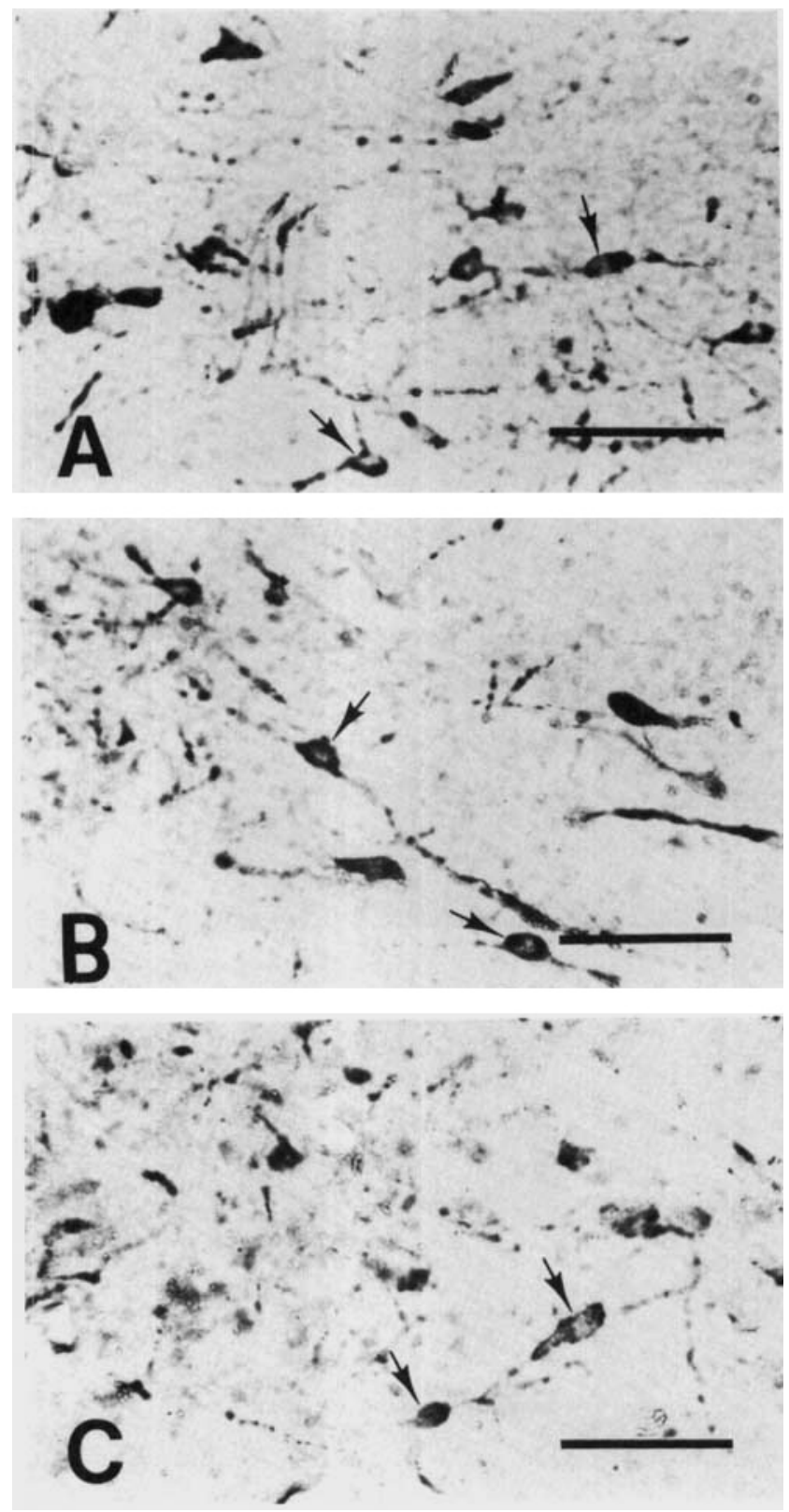

Fig. 18. These three consecutive frontal sections through the mesencephalon demonstrate tegmental perikarya (arrows) immunoreactive to $\beta$-endorphin (A), ACTH (B), and $\alpha$-MSH (C). Note also the various processes emanating from these perikarya. The animal was pretreated with $25 \mu \mathrm{g}$ colchicine, ICV. Bars $(\mathrm{A}, \mathrm{B}, \mathrm{C})=50 \mu \mathrm{m}$.

mesencephalon of the lizard brain. In the rodent, this area corresponds to a region just dorsal to the substantia nigra, in which POMC immunoreactivity is confined to fibers of passage belonging to one of the caudal projectional systems arising from the arcuate POMC perikarya (see Khachaturian et al., '84). No immunoreactive perikarya are seen in the rodent mesencephalon. Further studies are needed to determine whether or not the extent of either cell group in the lizard brain can be attributed to differences in perikaryal size (see Results). Furthermore, there appears to be yet
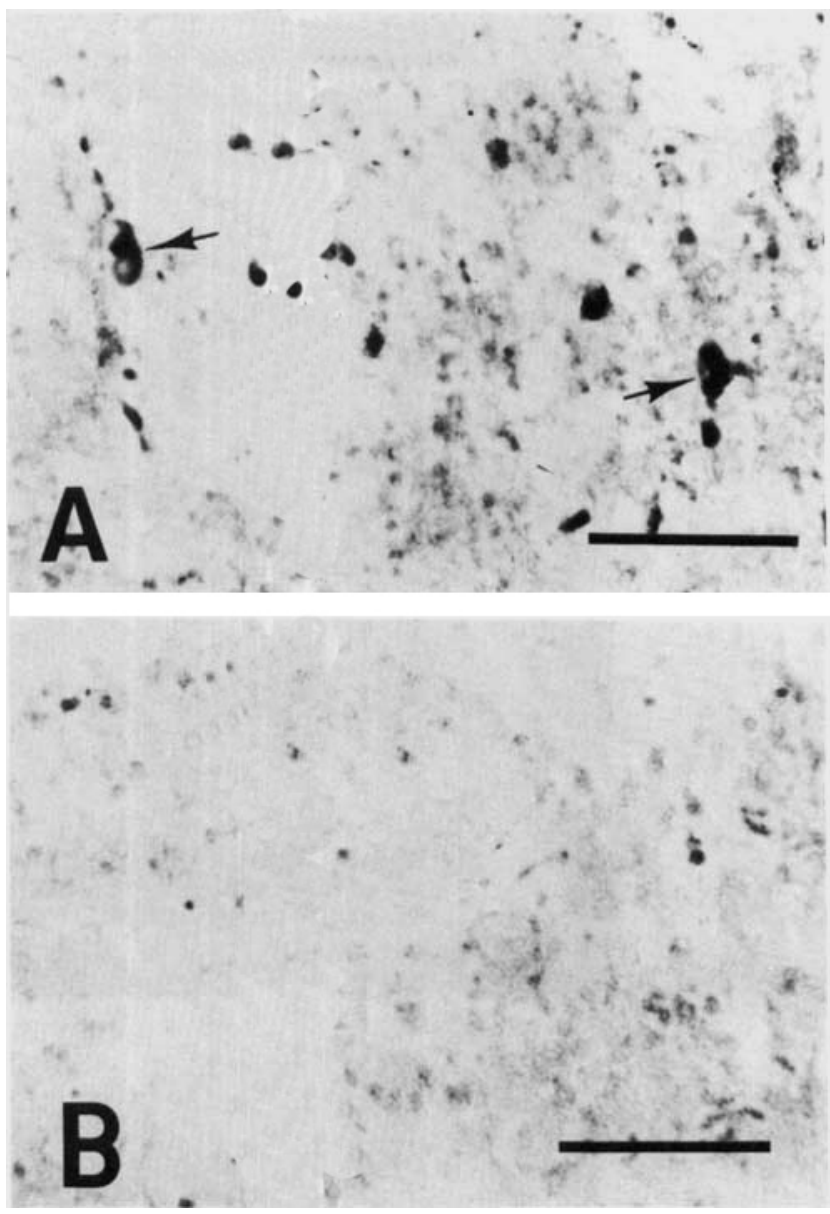

Fig. 19. One result of the blocking studies is depicted in these two adjacent sections. Panel $\mathrm{A}$ shows immunoreactive $\beta$-endorphin perikarya (arrows) in the mesencephalic tegmentum. In section $B$, the $\beta$-endorphin antiserum was absorbed by $1 \mu \mathrm{M} \beta$-endorphin peptide prior to incubation, resulting in the complete blockade of specific immunoreactivity. Bars $=50$ $\mu \mathrm{m}$.

another major difference in perikaryal localization sites between the two species. A recently discovered POMC neuronal population apparently resides in the caudal nucleus tractus solitarius pars nucleus comissuralis in the dorsomedial medulla of the rat (Schwartzberg and Nakane, '83; Joseph et al., '83; Khachaturian et al., '83). This is a modest population, only demonstrable upon pretreatment of the animal with relatively high doses of colchicine. In the present study, however, we were unable to locate such immunoreactive perikarya in the lizard nucleus tractus solitarius. Whether this can be attributed to technical problems such as those encountered in demonstrating the equivalent rodent neurons will remain unanswered pending further analyses with higher doses of colchicine or other technical improvements.

As for fiber projectional systems, several differences and similarities between the rat and the lizard are noteworthy. The rostral projections which appear to arise from the arcuate neurons in both species are strikingly similar, innervating midline hypothalamic, preoptic, and limbic te- 

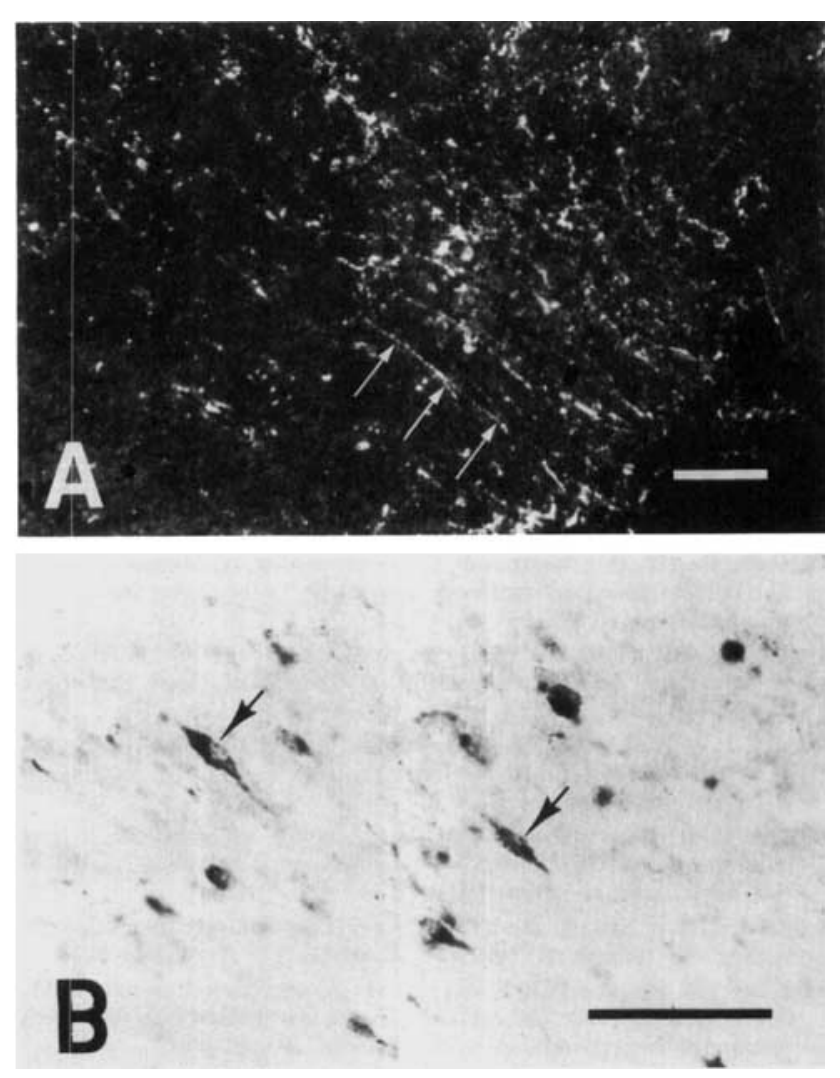

Fig. 20. These two adjacent parasagittal sections show the direction of fiber flow in the mesencephalon (arrows in A) which appear in parallel to the orientation of immunoreactive perikarya shown in B (arrows). These neurons contribute to the innervation of the mesencephalic central gray and other brain stem structures. A. In darkfield $\beta$-endorphin fiber immunoreactivity, B. ACTH immunoreactivity in a colchicine-pretreated animal. $\operatorname{Bar}(A)=100 \mu \mathrm{m} ; \operatorname{bar}(B)=50 \mu \mathrm{m}$.

lencephalic structures. However, unlike in the rodent, the lizard bed nucleus of stria terminalis does not appear to be an area of particularly dense innervation. In fact, the entire rostral projectional system is less pronounced in the lizard brain than in the rodent brain. However, additional areas of innervation in the lizard telencephalon include the ventral striatum and the medial cortex, areas that are virtually devoid of immunoreactive fibers in the rodent. Likewise, the lateral projections of the arcuate neurons appear less well developed in the lizard than in the rat; the amygdaloid area in the lizard received only a scant innervation. In the midbrain, however, the POMC-peptide-immunoreactive perikarya in the lizard give rise to a distinct dorsal projection which appears to innervate the mesencephalic central gray. A rather minor projection of the latter neurons courses in the ventral pons and medulla, innervating the reticular and raphe nuclei, and it probably also contributes fibers to the spinal cord. In the rodent, it is assumed that the major source of brainstem innervation is the arcuate POMC-producing neurons, with the possible exception of the relatively minor projections of the POMCcontaining neurons in the nucleus tractus solitarius. These latter perikarya apparently contribute projections to areas situated more dorsally in the medulla and pons, e.g., the
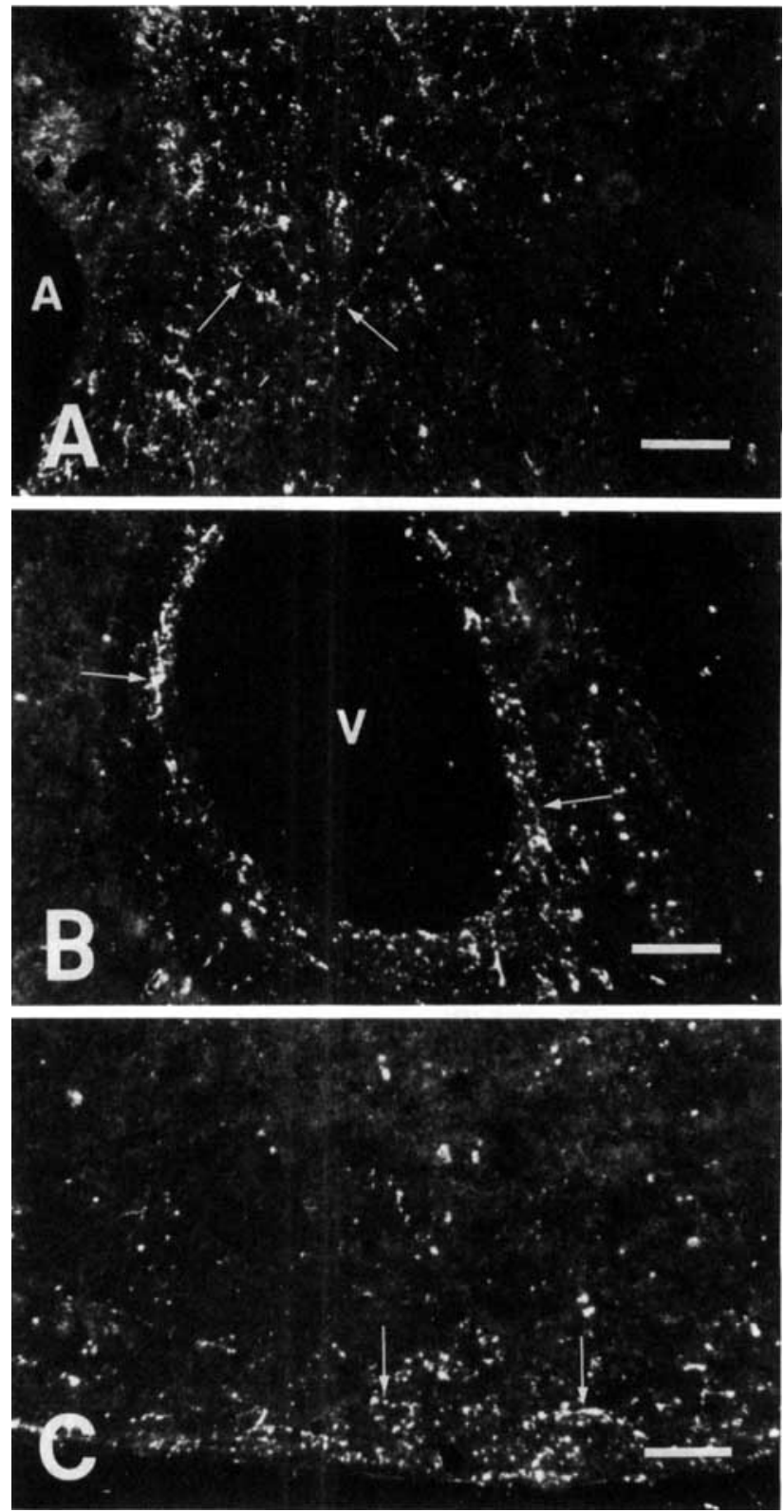

Fig. 21. Immunoreactive $\beta$-endorphin fibers (arrows) are shown in three separate parasagittal sections, under darkfield conditions. A. Mesencephalic central gray. B. Subependymal fibers in the tectum. C. Reticular nucleus in the ventral medulla. See list of abbreviations. Bars $(A, B, C)=$ $100 \mu \mathrm{m}$.

parabrachial nuclei (Schwartzberg and Nakane, '83; Joseph et al., '83). In contrast, only a few scattered fibers were noted in the dorsal pons and medulla of the lizard brain, including the nucleus tractus solitarius.

On the basis of these observations, it appears that major differences exist between the lizard and the rat with regard to the anatomical organization of the POMC-containing neuronal systems. Whether these differences contribute to dissimilar functions is not known. Thus, further functional studies as well as further biochemical characterizations of 
POMC processing in the lizard brain (Dores et al., '84) should shed light on the evolutionary significance of this important neuromodulatory system in the brain.

\section{ACKNOWLEDGMENTS}

This work was supported by NIDA grant DA02265 to S.J.W. and H.A., and NIMH training grant MH15794 to H.K. We wish to thank Dr. Elizabeth Eipper and Dr. Richard Mains for providing $16 \mathrm{~K}$ fragment antiserum and Dr. Tong Joh for providing tyrosine hydroxylase antiserum. We are grateful to Dr. Joseph LaPointe for his aid in obtaining reptile anatomical atlases. The authors also wish to thank Dr. Michael E. Lewis for his critical reading of the manuscript, J. Liu and M. Fitzsimmons for technical assistance, and A. Henry for manuscript preparation.

\section{LITERATURE CITED}

Bloom, F.E., J. Rossier, E.L.F. Battenberg, A. Bayon, E. French, S.J. Henricksen, G.R. Siggins, D. Segal, R. Browne, N. Ling, and R. Guillemin (1978) Beta-Endorphin: Cellular localization, electrophysiological and behavioral effects. In E. Costa and M. Trabucchi (eds): The Endorphins: Advances in Biochemical Psychopharmacology, Vol. 18. New York: Raven Press, pp. 89-109.

Butler, A.B., and R.G. Northeutt (1973) Architectonic studies of the dien cephalon of Iguana iguana (Linnaeus). J. Comp. Neurol. 149:439-462.

Cruce, J.A.F. (1974) A cytoarchitectonic study of the diencephalon of the Tegu lizard, Tupinambis nigropunctatus. J. Comp. Neurol. 153:215-238.

Doerr-Schott, J., M.P. Dubois, and C. Licht (1981) Immunohistochemical localization of substances reactive to antisera against alpha- and betaendorphin and met-enkephalin in the brain of the Rana temporaria L. Cell Tissue Res. 217:79-92.

Dores, R.M. (1982a Localization of multiple forms of ACTH- and betaendorphin-related substances in the pituitary of the reptile, Anolis carolinensis. Peptides. 3:913-924.

Dores, R.M. (1982b) Evidence for a common precursor for alpha MSH and beta-endorphin in the intermediate lobe of the pituitary of the reptile Anolis carolinensis. Peptides 3:925-935.

Dores, R.M. (1983) Further characterization of the major forms of reptile beta-endorphin. Peptides 4:897-905.

Dores, R.M., H. Khachaturian, S.J. Watson, and H. Akil (1984) Localization of neurons containing pro-opiomelanocortin-related peptides in the hypothalamus and midbrain of the Lizard, Anolis carolinensis: evidence for region specific processing of beta-endorphin. Brain Res. (in press).

Dores, R.M., and A. Surprenant (1983) Biosynthesis of multiple forms of beta-endorphin in the reptile intermediate pituitary. Peptides 4 : 889-896.

Dores, R.M., and A. Surprenant (1984) In vitro synthesis of ACTH- and betaendorphin-related substances in the pars distalis of Anolis carolinensis. Gen. Comp. Endocrinol, (in press).

Dubois, M.P., R. Billard, B. Breton, and R. Petor (1979) Comparative distribution of somatostatin, $\mathrm{LHRH}$, neurophysin and alpha-endorphin in the rainbow trout: an immunocytochemical study. Gen. Comp. Endocrinol. 37:220-232.

Eipper, B.A., and R.E. Mains (1980) Structure and function of pro-adrenocorticotropin/endorphin and related peptides. Endocrinol. Rev. 1: $247-262$.

Fink, B.R., M. Byers, and M. Middaugh (1973) Dynamics of colchicine effects on rapid axonal transport and axonal morphology. Brain Res. 56: $299-311$.

Finley, J.C.W., P. Lindstrom, and P. Petrusz (1981) Immunocytochemical localization of beta-endorphin-containing neurons in the rat brain. Neuro-endocrinol. 33:28-42.
Follenius, E., and M.P. Dubois (1979) Localisation des sites immunoreactifs avec un antiserum contre la met-enkephaline et contre l'alpha-endor phine dans le cerveau de la Carpe. C.R. Acad. Sci. (Pairs) 288:903-908.

Goldschmidt, R.B., and O. Steward (1982) Neurotoxic effects of colchicine: differential susceptibility of CNS neuronal populations. Neuroscience 7:695-714.

Greenberg, N. (1982) A forebrain atlas and stereotaxic technique for the lizard, Anolis carolinensis. J. Morphol 174:214-236.

Jacobowitz, D.M., and T.L. O'Donohue (1978) Alpha-melanocyte-stimulating hormone: immunocytochemical identification and mapping in the neurons of the rat brain. Proc. Natl. Acad. Sci. U.S.A. 75:6300-6304.

Joseph, S.A., W.H. Pilcher, and C. Bennett-Clarke (1983) Immunocytochemical localization of ACTH perikarya in nucleus tractus solitarius: Evidence for a second opiocortin system. Neurosci. Lett. 38:221-225.

Khachaturian, H., M.E. Lewis, K. Tsou, and S.J. Watson (1984) Beta-endorphin, ACTH, alpha-MSH and related peptides. In T. Hokfelt and A. Bjorklund (eds): Handbook of Chemical Neuroanatomy, v. 3. Amsterdam: Elsevier Biomedical Publishers, in press.

Khachaturian, H., S.J. Watson, M.E. Lewis, D. Coy, A. Goldstein, and H. Akil (1982) Dynorphin immunocytochemistry in the rat central nervous system. Peptides 3:941-954.

Kreutzberg, G.W. (1969) Neuronal dynamics and axonal flow. IV. Blockage of intraaxonal transport by colchicine. Proc. Natl. Acad. Sci. U.S.A. 62:722-728.

Krieger, D.T., A.S. Liotta, M.J. Brownstein, and E.A. Zimmerman (1980) ACTH, beta-endorphin and related peptides in brain, pituitary, and blood. Rec. Prog. Horm. Res. 36:277-345.

Li, C.H. (1981) Beta-endorphin: Synthetic analogs and structure-activity relationships. In C.H. Li (ed): Hormonal Proteins and Peptides, Vol. 10. New York: Academic Press, pp. 2-30.

Mains, R.E., B.A. Eipper, and N. Ling (1977) Common precursor to corticotropins and endorphins. Proc. Natl. Acad. Sci. U.S.A. 74:3014-3018.

Naik, D.R., M. Sar, and W.E. Stumpf (1981) Immunohistochemical localization of enkephalin in the central nervous system and pituitary of the lizard, Anolis carolinensis. I. Comp. Neurol. 198:583-601.

Nakanishi, S., A. Inoue, T. Kita, M. Nakamura, A.C.Y. Chung, S.N. Cohen, and S. Numa (1979) Nucleotide sequence of cloned cDNA for bovine corticotropin-beta-lipotropin precursor. Nature 278:423-427.

Nilaver, G., E.A. Zimmerman, R. Defendini, A. Liotta, D.A. Krieger, and M.J. Brownstein (1979) Adrenocorticotropin and beta-lipotropin in the hypothalamus. Localization in the same arcuate neurons by sequential immunocytochemical procedures. J. Cell Biol. 81:50-58.

Northcutt, R.G. (1978) Forebrain and midbrain organization in lizards and its phylogenetic significance. In N. Greenberg and P.D. MacLean (eds): Behavior and Neurology of Lizards. NIMH., Washington: U.S. Government Printing Office pp. 11-64.

O'Donohue, T.L., and D. Dorsa (1982) The opiomelanotropinergic neuronal and endocrine systems. Peptides 3:353 395.

Roberts, J.L., and E. Herbert (1977) Characterization of a common precursor to corticotropin and beta-lipotropin: Identification of beta-lipotropin peptides and their arrangement relative to corticotropin in the precursor synthesized in a cell-free system. Proc. Natl. Acad. Sci. U.S.A. 74: 5300-5304.

Schwartzberg, D.G., and P.K. Nakane (1983) ACTH-related peptide neurons within the medulla oblongata of the rat. Brain Res $276: 351-356$.

Sofroniew, M.V. (1979) Immunoreactive beta-endorphin and ACTH in the same neurons of the hypothalamic arcuate nucleus in the rat. Am J. Anat. 154:283-289.

Watson, S.J., H. Akil, C.W. Richard, and J.D. Barchas (1978) Evidence for two separate opiate peptide neuronal systems. Nature 275:226-228.

Watson, S.J., H. Akil, and J.M. Walker (1980) Anatomical and biochemical studies of the opioid peptides and related substances in the brain. Peptides, 1 [suppl. 1]:11-20. 